Л Е Ц И Я

лечения больных РА с различными поражениями плечевого пояса. На этапе стационарного лечения проводилась топическая диагностика поражения элементов этой области у 71 больного РА, которому был проведен полный комплекс мероприятий консервативной ревмоортопедии (основная группа). 35 пациентов с аналогичной патологией, получавших традиционное терапевтическое лечение, составили контрольную группу. Отличные и хорошие результаты лечения были получены у $60 \%$ больных основной и $17 \%$ контрольной группы (различия статистически достоверны). Через 1 год наблюдения в условиях поликлинического этапа сохранность положительных результатов комплексной кон- сервативной ревмоортопедии в 3 раза чаще регистрировалась в основной группе по сравнению с контрольной.

Итак, профилактика и лечение различных поражений двигательных элементов плечевого пояса включают в себя лечение положением, ЛФК и локальную терапию ГК на фоне адекватного антиревматического медикаментозного лечения. Кроме того, обязательно используются реабилитационные установки типа УГУЛ и РУП, а также трудотерапия.

В следующих сообщениях мы поделимся опытом консервативной ревмоортопедии при ревматических заболеваниях других отделов опорно-двигательного аппарата.

\title{
Л И Т
}

1. Sliva A.C. et al. Effectiveness of night time hand positioning splint in rheumatoid arthritis: a randomized controlled trial. J Rehabil med 2008;40(9):749-54.

2. Kiekenbeck A., Preis M., Salzman G. Rheumatoid shoulder: Does minimally invasive therapy make sense? Z Rheumatol 2008;67(6):462-70.

3. Павлов В.П. Ревмоортопедия ювенильного артрита в клинической практике Института ревматологии РАМН. Науч- практич ревматол 2005;4:98-101.

4. Павлов В.П., Павленко Т.М., Арсеньев А.О. и др. Принципы реабилитации ревматологических больных. Научпрактич ревматол 2005;2:70-5.

5. Шелепина Т.А. Принципы реабилитационного лечения детей с хроническими воспалительными заболеваниями суставов. Труды научного конгресса по проблеме социальной медицинской и психологической реабилитации инвалидов. Тю- мень, 1996;116.

6. Вершинин А.Е., Мылов Н.М.,

Павлов В.П. Артрографическая оценка патологии мягких тканей в комплексном исследовании плечевых суставов с различной степенью нарушения двигательной функции у больных ревматоидным артритом. Ревматол 1988;1:22-8.

7. Вершинин А.Е. Приспособление для разработки движений в плечевом суставе. Ортоп травматол 1987;6:54-5.

\section{Курация больных с ревматическими пороками сердца в амбулаторных условия Х}

\section{Б.С. Белов, Г.М. Тарасова, М.В. Полянская \\ ГУ НИИ ревматологии РАМН, Москва}

Сформулированы основные задачи диспансеризации больных с ревматическими пороками сердиа (РПС) на основе базовых положений рекомендаций международных и национальных научных ассоциаций. В то же время, по мнению автора, важная роль в курации больных с хронической ревматической болезнью сердиа и РПС принадлежит опыту и суждениям клинициста.

\section{Follow-up of patients with rheumatic heart diseases in the outpatient setting \\ B.S. Belov, G.M. Tarasova, M.V. Polyanskaya \\ Institute of Rheumatology, Russian Academy of Medical Sciences, Moscow}

The major tasks of a follow-up of patients with rheumatic cardiac defects (RCD) are formulated on the basis of the recommendations of international and national scientific associations. At the same time, a clinicianXs experience and judgments play an important role in supervising patients with chronic rheumatic heart disease and $R C D$.

Острая ревматическая лихорадка (ОРЛ) и хроническая ревматическая болезнь сердца (ХРБС) принадлежат к группе внутренних заболеваний, в лечении и профилактике которых достигнуты существенные успехи. Это привело к тому, что во второй половине XX столетия заболеваемость ОРЛ и ХРБС и обусловленная ими смертность снизились, а продолжительность жизни больных увеличилась. Снижение заболеваемости было тесно связано с повышением уровня жизни, улучшением качества медико-профилактических мероприятий. Однако, по данным статистического отчета Минздравсоцразвития РФ за 2007 г., распространенность ХРБС и ревматических пороков сердца (РПС) остается высокой и составляет 2,09 и 1,66 на 1000 населения соответственно. Следовательно, по-прежнему сохраняется как общемедицинское, так и соци- альное значение адекватного и качественного диспансерного наблюдения больных ХРБС и РПС.

Основные задачи диспансеризации больных ХРБС и РПС сводятся к следующему:

- регулярный медицинский осмотр с проведением необходимых дополнительных исследований;

- вторичная профилактика повторных атак ОРЛ;

- профилактика инфекционного эндокардита;

- терапия хронической сердечной недостаточности;

- решение (совместно с кардиохирургами) вопросов хирургической коррекции РПС;

- профилактика тромбоэмболических осложнений.

Все больные РПС должны проходить как минимум ежегодное обследование. При наличии умеренной клапанной 
Л Е И И Я

Таблица 1. Группы риска развития ИЭ

\section{Группа высокого риска:}

искусственные клапаны сердца

(включая биопротезы и аллотрансплантаты)

ИЭ в анамнезе

сложные «синие» врожденные пороки сердца

(тетрада Фалло, транспозиция крупных артерий и др.)

оперированные системные легочные шунты

\section{Группа умеренного риска:}

неоперированные врожденные пороки сердца: открытый артериальный проток, дефект межжелудочковой перегородки, первичный дефект межпредсердной перегородки, коарктация аорты, двустворчатый аортальный клапан приобретенные пороки сердца гипертрофическая кардиомиопатия пролапс митрального клапана с митральной регургитацией и/или утолщением створок

регургитации ЭхоКГ выполняют ежегодно. У больных с выраженной клапанной регургитацией врачебный осмотр и ЭхоКГ проводят каждые 6 мес. При появлении жалоб на сердцебиение целесообразно проведение холтеровского мониторирования для диагностики нарушений ритма сердца.

Вторичная профилактика направлена на предупреждение повторных атак и прогрессирования заболевания у лиц, перенесших ОРЛ, и предусматривает регулярное круглогодичное введение пенициллина пролонгированного действия (бензатин бензилпенициллин). Препарат вводят глубоко внутримышечно детям с массой тела $<27$ кг в дозе 600000 ЕД 1 раз в 3 нед, детям с массой тела > 27 кг - 1200000 ЕД 1 раз в 3 нед, подросткам и взрослым - 2400000 ЕД 1 раз в 3 нед.

Длительность вторичной профилактики (которую следует начинать еще в стационаре) для каждого пациента устанавливается индивидуально и в соответствии с рекомендациями ВO3 [1] определяется наличием факторов риска повторных атак ОРЛ. К этим факторам относятся: возраст больного; наличие ХРБС; время от момента первой атаки ОРЛ; число пре-
Таблица 2. Показаниякантибиотикопрофилактике ИЭ

Стоматологические манипуляции с риском повреждения десен и слизистой оболочки полости рта

\section{Дыхательные пути:}

тонзиллэктомия и/или аденотомия

операции с нарушением целостности слизистой оболочки бронхоскопия жестким бронхоскопом

Желудочно-кишечный тракт:

склеротерапия варикозно-расширенных пищеводных вен дилатация стриктуры пищевода

вмешательства на обтурированных желчных путях

\author{
Урогенитальный тракт: \\ трансуретральная резекция простаты \\ биопсия простаты или мочевыводящих путей \\ цистоскопия на фоне инфекции мочевых путей \\ дилатация уретры \\ литотрипсия \\ гинекологические манипуляции в присутствии инфекции
}

дыдущих атак; фактор скученности в семье; семейный анамнез, отягощенный по ОРЛ/ХРБС; социально-экономический и образовательный статус больного; риск стрептококковой инфекции в регионе; профессия и место работы больного (школьные учителя, врачи, лица, работающие в условиях скученности). Как правило, длительность вторичной профилактики должна составлять: а) для лиц, перенесших ОРЛ без кардита (артрит, хорея), - не менее 5 лет после последней атаки или до 18-летнего возраста (по принципу «что дольше»); б) в случаях излеченного кардита без формирования порока сердца - не менее 10 лет после последней атаки или до 25-летнего возраста (по принципу «что дольше»); в) для больных с пороком сердца (в том числе после операции) - пожизненно.

Наиболее эффективной лекарственной формой бензатин бензилпенициллина является экстенциллин. Исследования, проведенные в Институте ревматологии РАМН и Го-

\section{Таблица 3. Рекомендуемые схемы профилактики ИЭ при различныхмедицинскихманипуляииях}

\begin{tabular}{lcc} 
Область манипуляции & Исходные условия & Антибиотик и схема приема \\
\hline $\begin{array}{l}\text { Полость рта, пище- } \\
\text { вод, дыхательные пути }\end{array}$ & Стандартная схема & Амоксициллин 2 г (50 мг/кг) внутрь за 1 ч до процедуры \\
& Невозможность перорального приема & Ампициллин 2 г (50 мг/кг) в/в или в/м за 30 мин до процедуры \\
& Аллергия к пенициллинам & Клиндамицин 600 мг (20 мг/кг) или азитромицин/кларитромицин \\
& $\begin{array}{c}500 \text { мг (15 мг/кг) внутрь за } 1 \text { ч до процедуры } \\
\text { Аллергия к пенициллинам и невоз- } \\
\text { можность перорального приема }\end{array}$ & Клиндамицин 600 мг (20 мг/кг) в/в за 30 мин до процедуры \\
\hline
\end{tabular}

Желудочно-кишечный и урогенитальный тракт

$$
\text { Группа высокого риска }
$$

Группа высокого риска с аллергией к пенициллинам

Группа умеренного риска

Группа умеренного риска с аллергией к пенициллинам
Ампициллин 2 г (50 мг/кг) в/м или в/в плюс гентамицин 1,5 мг/кг (не $>120$ мг) в/м или в/в за 30 мин до процедуры; через 6 ч - ампициллин 1 г (25 мг/кг) в/м или в/в или амоксициллин 1 г (25 мг/кг) внутрь

Ванкомицин 1 г (20 мг/кг) в/в в течение 1-2 ч плюс гентамицин 1,5 мг/кг в/в или в/м (не >120 мг) - введение завершить за 30 мин до процедуры

Амоксициллин 2 г (50 мг/кг) внутрь за 1 ч до процедуры или ампициллин 2 г (50 мг/кг) в/м или в/в за 30 мин до процедуры

Ванкомицин 1 г (20 мг/кг) в/в в течение 1-2 ч - введение завершить за 30 мин до процедуры

Примечание. В скобках указаны дозы для детей до 12 лет; в/в - внутривенное, в/м - внутримышечное введение. 


\section{Л Е К Ц И Я}

сударственном научном центре по антибиотикам, показали, что экстенциллин обладает явными фармакокинетическими преимуществами по сравнению с бициллином-5 по основному параметру - длительности поддержания адекватной противострептококковой концентрации бензилпенициллина в сыворотке крови пациентов [2]. Из отечественных препаратов рекомендуется бициллин-1, который назначается в вышеуказанных дозах 1 раз в 7 дней.

В настоящее время препарат бициллин-5 (смесь 1200000 ЕД бензатин бензилпенициллина и 300000 ЕД новокаиновой соли бензилпенициллина) рассматривается как не соответствующий фармакокинетическим требованиям, предъявляемым к превентивным препаратам, и не является приемлемым для проведения полноценной вторичной профилактики ОРЛ.

Широко практиковавшееся ранее ежедневное применение эритромицина у больных с ОРЛ в анамнезе и непереносимостью $\beta$-лактамных антибиотиков сегодня нуждается в пересмотре из-за повсеместного нарастания резистентности БГСА к макролидам. Альтернативой у данной категории пациентов может служить своевременное курсовое лечение макролидами каждого случая БГСА-тонзиллита/фарингита.

Профилактика инфекционного эндокардита (ИЭ). В соответствии с рекомендациями Европейского кардиологического общества [3] все больные с РПС входят в группы риска развития ИЭ (табл. 1), им проводится антибиотикопрофилактика при определенных вмешательствах, влекущих за собой бактериемию, вызванную потенциальными возбудителями ИЭ (табл. 2). В табл. 3 представлены рекомендации по антибиотикопрофилактике при различных клинических ситуациях.

Наиболее частой причиной ИЭ, развивающегося после манипуляций в ротовой полости, дыхательных путях и пищеводе, является Str. viridans. Рекомендуемая стандартная схема профилактики стрептококкового ИЭ - однократный прием амоксициллина (2 г внутрь), который превосходит по биодоступности ампициллин и феноксиметилпенициллин. При этом сывороточная концентрация амоксициллина, в несколько раз превышающая МПК для большинства стрептококков, поддерживается по меньшей мере 6 ч, и повторное применение препарата не требуется.

К несомненным достоинствам следует отнести наличие амоксициллина в диспергируемой лекарственной форме Солютаб (Флемоксин Солютаб, «Астеллас Фарма»), обладающей благоприятными фармакокинетическими свойствами (высокая биодоступность, равномерное нарастание концентраций действующего вещества в крови), минимальным воздействием на микрофлору кишечника, при этом диспепсические расстройства наблюдаются реже. Не менее важным представляется удобство применения данной лекарственной формы (проглатывание целиком, разжевывание или предварительное растворение в воде), что повышает точность исполнения пациентами предписанной схемы.

Важно подчеркнуть, что схема приема антибиотиков, назначаемых с целью профилактики повторных атак ревматической лихорадки, не совпадает с рекомендуемой для предупреждения ИЭ. В подобных ситуациях для профилактики ИЭ рекомендуется назначать макролиды (азитромицин, кларитромицин) или клиндамицин.

Подходы к терапии хронической сердечной недостаточности $(\mathrm{XCH})$ у больных ОРЛ и ХРБС имеют ряд особенностей. В частности, в случаях развития сердечной декомпенсации вследствие острого вальвулита (что, как правило, встречается только в детском возрасте) применение кардиотонических препаратов нецелесообразно, поскольку явный терапевтический эффект может быть достигнут при использовании высоких доз преднизолона (40-60 мг/сут). В то же время у больных ХРБС и ХСН без явных признаков кардита назначение глюкокортикоидов (ГК) неоправданно из-за усугубления прогрессирующей миокардиодистрофии. У пациентов с кардитом на фоне ХРБС при выборе препаратов для терапии ХСН следует учитывать их возможное взаимодействие с противовоспалительными лекарственными средствами.

Основные группы препаратов, применяемых для лечения ХСН у больных ОРЛ и ХРБС:

- диуретики: петлевые - фуросемид; тиазидные и тиазидоподобные - гидрохлортиазид, индапамид; калийсберегающие - спиронолактон, триамтерен;

- блокаторы кальциевых каналов из группы дигидропиридинов длительного действия (амлодипин);

- $\beta$-адреноблокаторы (карведилол, метопролол, бисопролол);

• сердечные гликозиды (дигоксин).

Дозы и схемы применения этих препаратов аналогичны таковым при лечении ХСН иной этиологии.

В последнее время в комплексном лечении ХCH у больных ХРБС значительно реже применяют нитраты из-за развития толерантности. Эти препараты также ухудшают прогноз заболевания у данной категории пациентов.

Вопрос о целесообразности использования ингибиторов ангиотензинпревращающего фермента (АПФ) у больных с кардитом на фоне ХРБС требует дальнейшего изучения. Известно, что ряд эффектов ингибиторов АПФ при $\mathrm{XCH}$ реализуется через активацию синтеза простагландинов и подавление разрушения брадикинина, также обладающего сосудорасширяющей активностью. В то же время основной механизм действия нестероидных противовоспалительных препаратов (НПВП), в частности диклофенака, являющегося препаратом выбора при повторных атаках ОРЛ, связан с ингибицией синтеза простагландинов. Следовательно, совместное назначение НПВП и ингибиторов АПФ может привести к ослаблению вазодилатирующего эффекта последних.

Показания к хирургическому лечению РПС определяются (в соответствии с последними рекомендациями Американской коллегии кардиологов и Американской кардиологической ассоциации [4]) с учетом морфологии пораженного клапана, выраженности клапанного стеноза или регургитации, вероятности тромбоэмболических осложнений, систолической функции левого желудочка (ЛЖ) и наличия симптомов ХСН.

Как правило, для хирургического лечения митрального стеноза (МС) используют баллонную митральную вальвулопластику (БМВП). Кроме того, применяют митральную комиссуротомию и протезирование митрального клапана (МК).

Показания для проведения БМВП:

- декомпенсация порока (XCH по NYHA II, III или IV $\left.\Phi^{*}\right)$ при умеренном или тяжелом стенозе и соответствующей морфологии МК, отсутствии тромба в левом предсердии и сопутствующей умеренной или тяжелой митральной регургитации (МР);

*Функциональный класс приведен в соответствии с классификацией Нью-Йоркской кардиологической ассоциации (1981). 
Л Е Ц И Я

- умеренный или выраженный МC с кальцинированными жесткими створками клапана, с XCH III-IV ФК, а также противопоказания к иному хирургическому лечению или его высокий риск.

Показания для проведения митральной комиссуротомии или протезирования МК:

- XCH III-IV ФК при умеренном или тяжелом МС, когда: невозможно выполнить БМВП; БМВП противопоказана в связи с тромбом в ЛП, несмотря на терапию антикоагулянтами или в связи с сопутствующей умеренной или тяжелой МР; морфология клапана не подходит для БМВП;

- умеренный или тяжелый МС и сопутствующая умеренная или тяжелая МР (показано протезирование МK, если невозможна пластика);

- тяжелый МС с легочной гипертензией (систолическое давление в легочной артерии $>60$ мм рт. ст.), симптомы ХСН I-II ФК, целесообразно протезирование МК (если не предполагается выполнение БМВП или комиссуротомии).

Показания к хирургическому вмешательству при МР:

- тяжелая МР, сопровождающаяся симптомами ХСН II-IV ФК при отсутствии тяжелой дисфункции ЛЖ (фракция выброса $<30 \%)$ и/или конечный диастолический размер > 55 мм;

- тяжелая МР при отсутствии симптомов ХCH, но сопровождающаяся легкой или умеренной дисфункцией ЛЖ (фракция выброса от 30 до 60\%) и/или конечный диастолический размер $\geqslant 40$ мм.

Реконструктивная операция (пластика МК) предпочтительнее, чем протезирование, у большинства больных с тяжелой МР. При этом пациентов необходимо направлять в кардиохирургические центры, имеющие опыт реконструктивных операций на МК.

При неишемической МР операция выбора - пластика MК независимо от возраста и необходимости выполнения коронарного шунтирования, т.е. пожилому пациенту с ревматической МР и сопутствующей ИБС при сохраненной функции ЛЖ показана именно пластика, а не протезирование МК. У лиц старше 60 лет после пластики МК по сравнению с протезированием отмечены меньшая операционная летальность и лучшая выживаемость при 15-летнем наблюдении.

Показания к хирургическому лечению аортального стеноза (AC):

- появление клинических симптомов при тяжелом АС (стенокардия, обмороки, одышка);

- запланированное коронарное шунтирование при тяжелом АC;

- запланированное вмешательство на аорте или других клапанах при тяжелом АC;

- тяжелый АС в сочетании с диастолической дисфункцией ЛЖ (ФВ $>50 \%)$;

- умеренный АC, если запланировано коронарное шунтирование, вмешательство на аорте или других клапанах сердца.

Показания к оперативному лечению при аортальной регургитации (АР):

- симптомы декомпенсации у больных с тяжелой АР независимо от систолической функции ЛЖ;
- хроническая тяжелая АР и систолическая дисфункция ЛЖ $(Ф В<50 \%)$ при отсутствии симптомов ХСН;

- запланированное коронарное шунтирование, вмешательство на аорте или других клапанах при тяжелой АР;

- протезирование АК целесообразно «бессимптомным» пациентам с тяжелой АР, нормальной функцией ЛЖ, но с его дилатацией (конечный диастолический размер >75 мм, конечный систолический размер >55 мм).

Профилактика тромбоэмболических осложнений. Одним из серьезных осложнений РПС являются тромбоэмболии, нередко приводящие к летальному исходу. Известно, что системные эмболии могут осложнять течение МС в 10-20\% случаев. Риск возникновения эмболий нарастает с возрастом и при наличии фибрилляции предсердий. Рандомизированные исследования непрямых антикоагулянтов у больных МС не проводились. Однако ретроспективные исследования показали, что назначение непрямых антикоагулянтов у больных с МС снижает частоту тромбоэмболий в 4-15 раз.

Показания к назначению непрямых антикоагулянтов при МС (целевой уровень МНО 2,0-3,0):

- фибрилляция предсердий (пароксизмальная, персистирующая или постоянная форма);

- тромбоэмболические феномены в анамнезе даже при сохраненном синусовом ритме;

- наличие тромба в ЛП;

- выраженный МС, увеличение ЛП по данным ЭхоКГ $(\geqslant 55$ мм $)$

- выраженный МС, расширение ЛП и спонтанный эхоконтраст при ЭхоКГ.

Показания к назначению антикоагулянтной терапии у больных с МР (целевой уровень МНО 2,0-3,0):

• постоянная или пароксизмальная фибрилляция предсердий;

• наличие системных эмболий в анамнезе;

- тромб в ЛП;

- в первые 3 мес после пластики МК.

Наличие механического клапанного протеза является показанием для пожизненной антикоагулянтной терапии. У больных с биопротезами терапия антикоагулянтами проводится как минимум в течение 3 мес, а при наличии осложняющих факторов (фибрилляция предсердий, тромбоэмболии в анамнезе, гиперкоагуляция, выраженная дисфункция ЛЖ с ФВ < 30\%) - также пожизненно.

Оптимальное значение МНО определяют с учетом тромбогенности протеза и факторов риска у больного (табл. 4.). 


\section{Л Е К ц и Я}

Таблица 5. Алгоритм насыщения Варфарином (таблетки 2,5 мг)

1-й день - 2 таблетки (5 мг) однократно вечером после ужина

2-й день - то же

3-й день - утром определяют МНО и берут мочу на анализ по Нечипоренко

МНО $<1,5$ - повышение суточной дозы на 1/2 таблетки, контроль МНО через 2 дня

МНО 1,5 - 2,0 - повышение суточной дозы на 1/4 таблетки, контроль МНО через 2 дня

MHO 2,0 - 3,0* - суточная доза без изменений, контроль МНО через 2 дня

МНО 3,0 - 4,0 - снижение суточной дозы на $1 / 4$ таблетки, контроль МНО через 2 дня

МHO > 4,0 - пропускают 1 прием, далее суточную дозу уменьшают на 1/2 таблетки, контроль МНО через 2 дня

5-й день - утром определяют МНО и берут мочу на анализ по Нечипоренко.

Действие соответствует алгоритму 3-го дня. Если срок подбора дозы длится более 5 дней, в дальнейшем МНО определяет 1 раз в 2 дня с применением алгоритма 3-го дня

Примечание. Звездочка - при наличии двух последовательных значений МНО в диапазоне от 2,0 до 3,0 следующее измерение выполняют через 1 нед, после чего при значении МНО 2,0-3,0 доза считается подобранной, в дальнейшем МНО определяют 1 раз в месяц. Для реципиентов клапанных протезов целевой диапазон МНО составляет 2,5-3,5, при этом алгоритм насыщения такой же.

В соответствии с международными рекомендациями [4, 5] препаратом выбора из группы антикоагулянтов-антагонистов витамина К является Варфарин («Никомед»), эффективность которого доказана в многочисленных клинических исследованиях. Алгоритм насыщения Варфарином представлен в табл. 5 .

Основные показания к назначению антиагрегантов у больных РПС (применяют ацетилсалициловую кислоту в дозе 50-150 мг/сут):

- развитие эмболических осложнений или формирование тромба ЛП у больных с митральными пороками сердца и фибрилляцией предсердий на фоне приема антикоагулянтов*;

- выраженный кальциноз митрального кольца у больных с митральными пороками и синусовым ритмом при развитии системной эмболии, ишемического инсульта или преходящего нарушения мозгового кровообращения; в случае возникновении повторных тромбоэмболических феноменов назначают терапию антикоагулянтами;

- наличие факторов риска тромбоэмболии (фибрилляция предсердий, гиперкоагуляция, низкая ФВ ЛЖ, сопутствующее атеросклеротическое поражение сосудов) у больных с механическими клапанными протезами на фоне лече- ния антикоагулянтами*; антиагреганты не назначают пожилым и лицам, имеющим в анамнезе указания на кровотечения из желудочно-кишечного тракта;

- развитие тромбоэмболии у больных с механическими клапанными протезами на фоне целевого МНО при лечении антикоагулянтами и невозможности повышения дозы последних*;

- отсутствие факторов риска тромбоэмболии у больных с биологическими протезами в митральной позиции и синусовым ритмом после 3 мес терапии антикоагулянтами (см. выше).

Заключение. При подготовке статьи авторы использовали базовые положения действующих рекомендаций международных и национальных научных ассоциаций [3-6]. Однако хотелось бы подчеркнуть, что изложенные материалы являются «не догмой, а руководством к действию». Многоплановость клинической практики невозможно уложить в рамки жесткой схемы. Поэтому решающая роль в курации больных ХРБС и РПС (как и пациентов с иной патологией) принадлежит опыту и суждениям клинициста.

*Ацетилсалициловую кислоту назначают дополнительно к проводимой терапии антикоагулянтами.
1. Rheumatic fever and rheumatic heart disease/WHO technical report series № 923. Geneva, 2004;122 p.

2. Белов Б.С., Черняк А.В., Сидоренко С.В. и др. Применение бензатин-пенициллина для вторичной профилактики ревматизма: проблемы и подходы к их решению. Науч-практич ревматол 2000;2:30-6.

3. Horstkotte D., Follath F., Gutschik E. et al. Guidelines on prevention, diagnosis and treatment of infective endocarditis executive summary; the task force on infective endocarditis of the European society of cardiology. Eur Heart J 2004;25(3):267-76.

4. Bonow R.O., Carabello B.A., Chatterjee K. et al. 2008 focused update incorporated into the ACC/AHA 2006 guidelines for the management of patients with valvular heart disease. Circulation 2008;118:523-661. 5. Vahanian A., Baumgartner H., Bax J. et al. Guidelines on the management of valvular heart disease. The task force on the management of valvular heart disease of thr European Society of Cardiology. Eur Heart J 2007;28: 230-68.

6. Hirsh J., Guyatt G., Albers G.W. et al. College of Chest Physicians. Antithrombotic and thrombolytic therapy. Executive summary: American College of Chest Physicians Evidence-Based Clinical Practice Guidelines (8th Edition). Chest 2008;133(6 Suppl.):71-109. 